\title{
Você não tem liberdade de expressão, de fato, a menos que também tenha acesso à informação ${ }^{1}$
}

DOI: https://doi.org/10.1590/1809-58442020212

\section{Toby Mendel ${ }^{1}$}

\section{Entrevista concedida a:}

\section{Luma Poletti Dutra ${ }^{2}$}

https://orcid.org/0000-0003-0834-6359

${ }^{1}$ (Centre for Law and Democracy. Halifax, Canadá).

${ }^{2}$ (Universidade de Brasília, Faculdade de Comunicação, Programa de Pós-Graduação em Comunicação. Brasília - DF, Brasil).

Toby Mendel é diretor-executivo da Centre for Law and Democracy, organização internacional com sede no Canadá que, desde 2010, realiza ações de defesa dos Direitos Humanos e fortalecimento da democracia, com foco em pesquisas sobre liberdade de expressão e direito de acesso à informação. Entre as atividades desenvolvidas pelo instituto, está

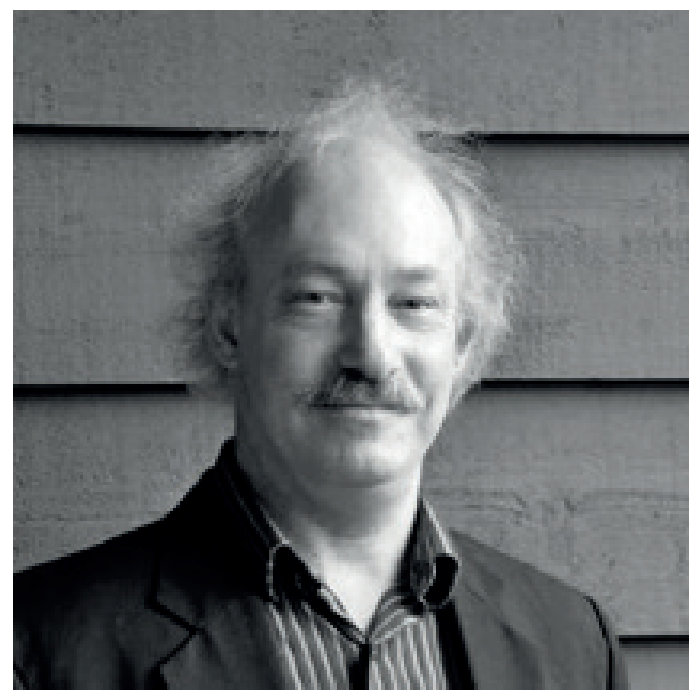
o Global Right to Information Rating ${ }^{2}$, uma ferramenta que classifica a força de leis de acesso à informação de diferentes países, com base em critérios pré-estabelecidos. Atualmente, a lista conta com 128 países e é encabeçada pelo Afeganistão, seguido pelo México. O Brasil está na $28^{a}$ posição.

Durante 12 anos, Mendel ocupou o cargo de diretor sênior da ONG Artigo 19 e já colaborou com diversos órgãos internacionais como Banco Mundial e UNESCO. Entre suas contribuições, destacam-se estudos sobre direito à informação, regulação da mídia e comunicação pública, como "Concentration of media ownership and freedom of expression: global standards and implications for Americas" (2017), "Serviço público de radiodifusão: um estudo de direito comparado" (2011) e "Liberdade de Informação: um estudo de direito comparado" (2009), todos publicados pela Unesco. Já foi consultor sênior de direitos

1 O presente trabalho foi realizado com apoio da Coordenação de Aperfeiçoamento de Pessoal de Nível Superior - Brasil (CAPES) Código de Financiamento 001.

2 Disponível em: https://www.rti-rating.org/country-data/. Acesso em: 28 maio 2020. 
humanos da Oxfam Canadá e trabalhou como analista de políticas de direitos humanos na Agência Canadense de Desenvolvimento Internacional.

A entrevista a seguir foi realizada durante a Conferencia Lationamericana de Periodismo de Investigación (Colpin), em novembro de 2019, na sede do Instituto Nacional de Transparencia, Acceso a la Información y Protección de Datos Personales (INAI), na Cidade do México. Entre os principais temas discutidos, estão a relação entre o direito de acesso à informação pública e a liberdade de expressão num contexto internacional.

Revista Intercom - Em 2009, você escreveu que a Lei de Acesso à Informação (LAI) do México era "depois do sistema da Suécia, talvez a garantia constitucional mais abrangente de direito à informação no mundo”. Dez anos depois, você mantém essa opinião?

Toby Mendel - Esse comentário foi sobre a estrutura legal no México e, na verdade, a estrutura legal no México melhorou significativamente. Esse comentário específico que você mencionou foi sobre a garantia constitucional. Na Suécia, toda a lei, todo o acesso à informação faz parte da Constituição, ninguém consegue superar isso. Mas, no México, há uma extensa garantia constitucional. Então isso é especificamente sobre Constituição e continua igual até hoje. Até onde eu saiba, ninguém mais estabeleceu uma garantia constitucional tão longa e detalhada, mas os mexicanos, desde 2009, e especificamente em 2015, adotaram uma nova Lei de Acesso à Informação de acordo com essa garantia constitucional. E, na época, o país foi para o topo das LAIs do mundo (minha organização possui esse sistema de classificação da qualidade da estrutura legal - estamos apenas falando sobre a estrutura legal, para ficar bem claro). Eles chegaram ao topo e agora o Afeganistão superou, mas eles ainda estão em segundo lugar, o que é obviamente fantástico. Muito acima da Suécia no âmbito legal. Mas é claro que a implementação é um assunto diferente.

Revista Intercom - É no mínimo curioso que países com longa tradição democrática não estejam no topo do Ranking Global de Direito à Informação? O Canadá, por exemplo, está em $58^{\circ}$ lugar.

Mendel - Este é um fenômeno interessante. Normalmente, países desenvolvidos se saem melhor em temas ligados aos direitos humanos. E o Canadá geralmente tem um bom desempenho nesse sentido, temos baixa desigualdade social, uma forte defesa da liberdade de expressão, bons sistemas de justiça criminal. Se olhar para todas as questões relacionadas aos direitos humanos, somos fortes nelas. O tema do acesso à informação surgiu nos países desenvolvidos como uma espécie de questão de governo. Pensou-se que seria bom abrir o governo, por exemplo, para promover accountability. Isso é bom, mas os países em desenvolvimento adotaram uma abordagem completamente diferente para esse tema. Para eles, é uma reforma dos direitos humanos. E há uma enorme diferença entre uma questão de direitos humanos e uma questão de governança. Então eu acho que se sair pelo México e perguntar às pessoas: "Você conhece o direito de acesso à informação? Você acha que é um direito humano?”, a maior parte vai dizer que sim. Se você perguntar isso aos canadenses, 
eles definitivamente não acham que é uma questão de direitos humanos. Portanto, essa é uma enorme diferença de abordagem do tema.

Revista Intercom - O que explica essa perspectiva diferente sobre o direito de acesso à informação entre os países?

Mendel - Se olhar, por exemplo, para os tribunais internacionais, o primeiro caso sobre esse assunto perante a Corte Europeia de Direitos Humanos ocorreu em 1985 e o tribunal rejeitou. Eles disseram: “Não, isso não faz parte da liberdade de expressão”. E, depois disso, eles rejeitaram muitas outras vezes. Em algumas situações, afirmaram que o direito de acesso à informação faz parte de temas como privacidade ou vida familiar. Você precisa da informação por motivos de privacidade ou por motivos familiares, mas não como parte da liberdade de expressão. Portanto, não é um direito geral à informação, mas se você precisar daquela informação específica por questões de privacidade, poderá obtê-la. Somente nessas situações muito delimitadas. E foi a Corte Interamericana de Direitos Humanos (em 2006, no caso Claude Reyes ${ }^{3}$ ) a primeira corte internacional a reconhecer o direito humano de acessar informações como parte do direito à liberdade de expressão. Você não tem liberdade de expressão, de fato, a menos que também tenha acesso à informação. Então, em 2009, a Corte Europeia percebeu: “Oh, estamos atrás”. A Corte Interamericana declarou integralmente: as exceções ao acesso à informação precisam atender aos padrões de exceção e tudo precisa atender aos padrões de direitos humanos. A Corte Europeia fez isso de uma maneira muito mais restrita. No meu país, a Suprema Corte do Canadá reconheceu o direito [de acesso à informação] se você precisar das informações para se expressar. Então eles o fizeram subordinado à expressão, não é um direito independente. Portanto, se você é um empresário que precisa das informações para a sua empresa, não será coberto [pela garantia legal], mas a maioria das pessoas está usando para se expressar. Isso foi em 2010 e não avançou desde então.

Revista Intercom - Quais são os desdobramentos dessas perspectivas diferentes entre os países?

Mendel - Isso mostra o quão pequeno estamos pensando esse tema em comparação aos países em desenvolvimento, que pensam muito maior. Portanto, é claro que geralmente os países desenvolvidos são mais bem organizados. Eles tendem a ter governos mais eficazes, são totalmente digitais, têm burocracias mais organizadas. Eles entregam o que está na lei mais ou menos melhor. No Canadá, por exemplo, (eu sei muito bem, porque faço muitos pedidos por lá) eles não infringem a lei, mas tentam de todas as maneiras usar a lei para negar o acesso. É como evitar pagar impostos, em oposição a sonegar impostos. No

3 No caso Claude Reyes versus Chile (2006), a Corte Interamericana de Direitos Humanos reconheceu o direito de acesso à informação pública como parte integrante do direito à liberdade de expressão e determinou que o Estado do Chile disponibilizasse as informações solicitadas por um grupo de ambientalistas em 1998, referentes a um projeto de extração de madeira. A Corte também sentenciou que o Chile adotasse padrões internacionais de legislação de acesso à informação pública. Disponível em: http://www.corteidh.or.cr/ docs/casos/articulos/seriec_151_esp.pdf. Acesso em: 28 maio 2020. 
primeiro caso, você tenta de todas as maneiras permitidas não pagar impostos. Por outro lado, ao sonegar impostos você infringe a lei. Portanto, eles permanecem tecnicamente dentro da lei, mas tentam usar todas as brechas da lei para negar as informações. Você realmente encontra isso no setor público. Nesse sentido, vocês têm uma atitude melhor e mais forte nos países do hemisfério Sul do que no Norte. Na verdade, eu gosto muito dessa questão. Eu acho ótimo que este seja um direito humano liderado por países do Sul, um dos poucos.

Revista Intercom - O Afeganistão lidera o ranking de Leis de Acesso à Informação. Você pode falar sobre a experiência deles com essa regra?

Mendel - O Afeganistão é um caso muito interessante. Eles aprovaram sua lei em 2014 e tinham uma lei fraca e uma Comissão de Acesso à Informação fraca. Por exemplo, na Comissão eles tinham um representante do serviço secreto. Não há país no mundo em que eles coloquem alguém assim em uma Comissão de Acesso à Informação, é loucura. O integrante da inteligência, o que ele está fazendo nessa comissão? Mas dentro da comissão eles também tinham alguns representantes da sociedade civil, pessoas independentes e essas pessoas assumiram o controle do grupo desde o início. A presidência, o secretário, o financeiro, eram todos membros da sociedade civil. O presidente em particular é um sujeito incrivelmente dinâmico da sociedade civil. E ele imediatamente reconheceu que a lei não era boa o suficiente para o Afeganistão e queria melhorá-la. Então, depois que o país passou por outra eleição presidencial, eles decidiram objetivamente que queriam levar o Afeganistão ao topo da classificação internacional de direito à informação. O verdadeiro articulador foi o presidente da comissão. Ele queria uma boa lei e conseguiu apoio político, inclusive por razões políticas. Por exemplo, o presidente eleito percebeu: "podemos usar isso para apresentar os doadores”. E depois que a lei deles alcançou o topo da classificação internacional, na próxima conferência de doadores, eles exibiram isso: "Vejam o progresso que o Afeganistão fez”, "Estamos à frente de todos neste tema”. O presidente da república tinha esse objetivo, mas o presidente da comissão só queria uma boa lei. E foi assim que eles conseguiram chegar ao topo do ranking.

Revista Intercom - Você pode explicar a relação entre políticas de acesso à informação pública e combate à corrupção?

Mendel - O que podemos dizer é que a abertura de informações é uma ferramenta importante para combater a corrupção. Quando você expõe abertamente um caso de corrupção, provavelmente se livrará dele (pelo menos daquele caso específico exposto). Uma vez exposto, é difícil continuar, isso nós podemos dizer. Mas, por outro lado, não vamos esquecer: a corrupção por definição já é um comportamento criminoso. O direito à informação é apenas uma lei, essas pessoas já estão infringindo uma lei; portanto, elas têm muitas habilidades e poder para evitar leis (incluindo leis de acesso à informação). Elas ocultam seu comportamento. É algo profundo e, por definição, muito secreto. Se você está 
no serviço público roubando dinheiro, você já está escondendo de outras pessoas que te rodeiam. Então isso é algo: já é contra a lei, é um comportamento criminoso. Em segundo lugar, quando a corrupção já está profundamente enraizada... por exemplo, no Canadá não temos tanta corrupção, não temos essa corrupção profunda. Portanto, o acesso à informação é bastante eficaz para ajudar a impedir a evolução de casos de corrupção. Mas, quando está enraizado - porque as pessoas envolvidas em corrupção obtêm um enorme benefício com isso, elas lutam até o fim para manter seus esquemas. Então elas já estão evitando a lei (direito penal) e também evitarão a lei de acesso à informação. Portanto, esse tipo de regra é eficaz, mas não pode por si só acabar com a corrupção.

Revista Intercom - Existem muitas Leis de Acesso à Informação que não se aplicam ao Poder Judiciário. Você acha importante que magistrados e tribunais também prestem contas? Mendel - Em geral juízes são muito arrogantes, eles pensam que estão acima de todos os outros e não veem o porquê devem prestar contas às pessoas comuns. Eu acho que é uma atitude negativa profundamente enraizada no Judiciário, mais forte do que em outras partes do governo. "Nós decidimos sobre você, não fale conosco", "Você decide sobre nós? Você está brincando? Somos nós que fazemos isso”. E acho que isso ocorre especialmente em sociedades mais tradicionais e hierárquicas. Se compararmos o Canadá à Grã-Bretanha, nossos juízes são muito mais abertos do que os juízes britânicos. Não por lei, mas apenas por natureza ou qualquer outro motivo, porque são menos hierarquizadas. A Grã-Bretanha é uma sociedade tradicional mais hierárquica. Então, acho que combinar a sociedade hierárquica e tradicional com essa atitude judicial é um grande problema. Eu imagino que muitos pensam: “Nós somos os juízes, quem é você para vir falar conosco?”.

Revista Intercom - Principalmente a partir dos anos 2000, o mundo assistiu a uma onda de aprovações de Leis de Acesso à Informação. Qual deve ser o próximo passo para efetivar esse direito?

Mendel - Com os Objetivos de Desenvolvimento Sustentável, uma das atividades à qual estamos nos dedicando é trabalhar no indicador número 16.10.2 - que questiona se os Estados adotaram e implementaram regras de acesso às informações. Estamos começando a desenvolver metodologias muito mais sofisticadas para avaliar como a implementação do acesso à informação está caminhando. Nosso ranking global mostra exatamente o quão forte é a estrutura jurídica, mas uma questão completamente diferente é se a implementação está indo bem. Então, acho que precisamos aplicar essas metodologias, descobrir os pontos fracos da implementação - que são muito sérios em todos os lugares, nenhum país está fazendo um trabalho perfeito. E depois trabalhar nesses pontos. É isso que precisamos fazer. É claro que em alguns países as leis não são tão boas, portanto elas precisam ser melhoradas, mas você tem leis decentes e muito boas na América Latina, isso é verdade. Então a implementação precisa ser o foco e acho que usar essas metodologias dará mais força, porque identificará claramente o que não está funcionando. Além disso, fornecerá 
uma avaliação objetiva orientada metodologicamente, em vez de apenas uma perspectiva de cidadãos que não acham que está funcionando.

Revista Intercom - E ao identificar o que não está funcionando, é possível tentar adequar a lei?

Mendel - Sim, para alterar a lei, acredito que os estudos já produzidos podem dizer tudo o que precisa para mudá-la, mas a implementação pode dizer: "sim, a lei existe, mas a maioria dessas autoridades públicas, os responsáveis pelo acesso à informação não são treinados”, por exemplo. Se os servidores não são treinados, não é possível aplicar a lei adequadamente, eles não serão capazes de fazer isso. É o seu trabalho, mas você não sabe como fazê-lo. É um encanador que não entende de encanamentos. Você não procuraria esse tipo de encanador, certo? Estou apenas dando um exemplo. A nova metodologia nos ajudaria a responder questões como: o órgão público sequer nomeou um servidor para lidar com o acesso à informação? Eles o treinaram? Eles lhe deram termos de referência? Como o trabalho está sendo feito? Devidamente? E assim por diante. Acho que essa metodologia pode ajudar.

Revista Intercom - Então a implementação das políticas de acesso à informação seria o próximo desafio?

Mendel - Sim, esse é o próximo passo. O primeiro passo é adotar a lei, depois o segundo passo é aplicá-la, e há muitas lacunas nisso.

\section{Referências}

MENDEL, T.; GARCÍA CASTILLEJO, A.; GÓMEZ, G. Concentration of media ownership and freedom of expression: global standards and implications for the Americas. Paris/Montevidéu: UNESCO, 2017. Disponível em: https://unesdoc.unesco.org/ark:/48223/pf0000248091. Acesso em: 23 jul. 2020.

MENDEL, T. Serviço Público de Radiodifusão: um estudo de direito comparado. Brasília: UNESCO, 2011. Disponível em: https://unesdoc.unesco.org/ark:/48223/pf0000214765?posInSet=3\&queryId=N-EXPLOREe2f0f14d-47d4-4f6a-93a8-0b9d993a58ae. Acesso em: 23 jul. 2020.

MENDEL, T. Liberdade de informação: um estudo de direito comparado. 2. ed. Brasília: UNESCO, 2009. Disponível em: https://unesdoc.unesco.org/ark:/48223/pf0000158450_por?posInSet=2\&queryId=NEXPLORE-604397b5-55e5-4847-9c2b-18e520bcacd1. Acesso em: 23 jul. 2020. 


\section{Luma Poletti Dutra (entrevistadora)}

Doutoranda do Programa de Pós-Graduação em Comunicação Social da Universidade de Brasília (UnB), com período de doutorado sanduíche no México, na Universidad Pedagógica Nacional (UPN). Integrante da Rede Nacional de Observatórios de Imprensa (RENOI), desenvolve pesquisas sobre direito de acesso à informação pública, accountability e comunicação pública. E-mail: lumadutra@ gmail.com.

Recebido em: 28.05.2020

Aprovado em: 24.07.2020 